\title{
Introduction to the themed issue - Poststructural approaches to fisheries
}

\author{
Charles Mather $^{1 *} \mathbb{D}$, Jahn Petter Johnsen ${ }^{2}$, Signe Sonvisen ${ }^{3}$, Aarthi Sridhar ${ }^{4}$ and Johny Stephen ${ }^{5}$
}

\author{
* Correspondence: \\ cmather@mun.ca \\ ${ }^{1}$ Memorial University of \\ Newfoundland, St. John's, Canada \\ Full list of author information is \\ available at the end of the article
}

\begin{abstract}
This themed issue of papers for Maritime Studies emerges out of a special session of the MARE 2015 conference held in Amsterdam. The aim of this Introduction is to provide a brief background to poststructural scholarship drawing on examples and cases from research on fisheries. We argue that a poststructural sensibility has made an important impact on scholars interested in fisheries issues even though it is not normally framed as such. An additional goal of this short introduction is to introduce the papers in this special issue of Maritime Studies and to situate them within the broad and heterogeneous field of post-structural approaches to fisheries issues.
\end{abstract}

\section{Introduction}

Poststructuralism offers a number of strategies for calling into question received ideas and dominant practices, making visible their power, and creating openings for alternative forms of practice and power to emerge (Gibson-Graham 2008, 97).

This themed issue for Maritime Studies emerges out of a special panel of the MARE 2015 conference focused on power and governmentality called 'The mechanics and technologies of power in marine geopolitics'. The special panel, which attracted 5 interesting papers, was run in an unconventional way. Rather than have 15 min long presentations followed by questions and answers, presenters had $5 \mathrm{~min}$ to present the key message of their research, followed by a short commentary by one of the other panel members. This unusual format set the stage for a long and engaged discussion between the presenters and a lively audience. The papers were subsequently revised for this special issue of Maritime Studies under the broader theme of 'Poststructural approaches to fisheries' research.

The aim of this Introduction is to provide a brief background to poststructural scholarship drawing on examples and cases from research on fisheries. We argue that poststructuralism has made an important impact on scholars interested in fisheries issues even though this work is not always framed in this way. Indeed, there is a rich vein of work on fisheries that draws on key concepts and ideas from poststructural thinkers including Michel Foucault, Bruno Latour, Michel Callon, John Law, Annemarie Mol and J.K. Gibson-Graham. A key goal of this introductory paper, and the special issue as a whole, is to highlight the significant impact that poststructural thinking has had in fisheries research.

A second goal of this Introduction is to introduce the papers in the themed issue of Maritime Studies and to situate them within the broad and heterogeneous field of

(c) The Author(s). 2017 Open Access This article is distributed under the terms of the Creative Commons Attribution 4.0 International License (http://creativecommons.org/licenses/by/4.0/), which permits unrestricted use, distribution, and reproduction in any medium, provided you give appropriate credit to the original author(s) and the source, provide a link to the Creative Commons license, and indicate if changes were made. 
poststructural scholarship. The papers have a strong empirical base and draw from different geographical contexts including India and Sri Lanka, Canada and Norway. While the focus of the case studies is different, the papers all share a common interest in exploring the potential of poststructural approaches to understanding fisheries issues including Actor Network Theory (ANT), Foucault's concepts power and discourse, and material-semiotic (or 'after-ANT') approaches most closely associated with the work of Annemarie Mol and John Law.

In this short review, we introduce poststructural thinking by tracing its emergence in the 1960s and we describe how it builds, and moves on, from an earlier tradition of structuralism. We then identify three 'strategies' associated with poststructural thought. These strategies are illustrated through published cases on fisheries issues and through the papers that make up this themed issue of Maritime Studies. Our aim in this introduction, and the themed issue, is to illustrate the significant impact that poststructural thinking has already had in the field of marine and fisheries research, and to suggest that there is scope for further engagement with this productive and engaging approach.

\section{Poststructuralism - Origins and first principles}

Poststructuralism as a field of scholarship defies easy definition, in part because the term is used to encompass considerable diversity in approach and conceptualisation, and because it does not always represent a clean break with structural approaches. An additional issue is that poststructural thought has emerged through the work of prominent scholars with somewhat divergent approaches, some of whom do not self identify as poststructuralist (see Howarth 2013). In spite of these caveats, it is possible to identify shared ideas and concepts associated with poststructural thinking, which have also been deployed by fisheries researchers. For reasons that will become clear in this introduction, and in the papers that make up the themed issue, there is no 'recipe', manual or easy-to-follow-diagram that describes poststructural thought and research practice. Instead, poststructuralism is best described as a toolkit of 'sensitising terms' and strategies that help us engage with the world (Mol, 2010; also see Gibson-Graham 2008; Law and Singleton 2014).

A starting point in most discussions of poststructuralism is the debt it owes to structuralism, an intellectual project that was developed in French linguistics and cultural studies (Howarth 2013; Williams 2005). While structuralism first emerged outside of the social sciences and humanities, its key insights were imported into cultural studies, economics and psychology through the work of prominent scholars like Claude LeviStrauss, Karl Marx and Sigmund Freud (Chaffee and Lemert 2009). Structuralists across these disciplines shared the common view that social life was determined by a set of underlying structures: "underlying the seemingly chaotic world of social relationships were 'elementary structures' of culture, whose discovery, it was hoped, would make clear the fundamental causes and limits of social life" (Amariglio 1998, 382). For structural scholars in the social sciences and humanities, the task was to reveal these underlying structures that were theorized to be central to understanding cultural, social and economic life. Structuralism provided a focus for research, yet it was much clearly more than simply an approach to cultural, social and economic problems. In conceptualising a world that was determined by underlying social structures, it also provided a theory about how the world 'works'. 
Poststructuralist thought emerged in the 1960s as a critical engagement with existing structuralist scholarship. Poststructuralists disagreed with the structural proposition that that abstractions (or structures) are responsible for social reality and that reality can only be understood in terms of these abstractions. Instead, they provided a radically different conceptualisation of the way the world 'works'. For poststructuralists, social formations (or societies) are the outcomes of heterogeneous practices, rather than underlying structures. These practices have the effect of bringing together - or assembling and networking - a wide range of diverse elements, including humans, other animals and things. The practice of assembling these heterogeneous elements is responsible for creating social formations or 'modes of ordering' that make up reality. In rejecting the significance of underlying social structures, poststructural thinking represented a dramatically different proposition about society and reality.

Several key implications follow from this poststructural proposition about how the world works, which are in turn helpful in revealing some of the fundamental differences between structural and poststructural thinking. First, because poststructuralists believe that social formations are the result of diverse and changing social practices and discourses, these social formations are necessarily indeterminate, precarious and contingent achievements. The 'social' for poststructural thinkers is always in the making, and in this way the structuralist concern with 'essence' is replaced by a concern with how the social 'becomes' (Howarth 2013, 61). Second, and following on from this first point, poststructuralists are less interested in the why of social formations and instead focus on the how of cultural, economic and social systems. Poststructuralists ask, 'How is it that these systems are able to sustain themselves, and through what mechanisms?' (Law 2009). Methodologically, this means that doing poststructural inspired research involves tracing how these heterogeneous assemblages emerge and are stabilized; once stabilized, poststructural researchers are interested in the effects of these assemblages or networks (Steinberg, 2011; Stephen, this issue; Sridhar, this issue). Poststructural approaches do not aim to provide $a$ theory about social, economic and ecological processes. In other words, it does not attempt to uncover and reveal "the 'deep' structures that determine 'surface' behaviour" (Murdoch, 2006, 10). Instead, poststructuralism involves tracing the heterogeneous socio-material networks that make up the world (Daniels and Mather, this issue). Rather than seeking to identify causes, the task is to examine the effects of these heterogeneous networks (Latour 2005; Sridhar this issue). Finally, poststructuralism always relies on demonstrating its theory empirically. Sometimes described as 'radical empiricism', poststructural scholarship has as its key aim to 'trace effects' through situated cases (Mol, 2010, 261; Latour 2005; Law 2008; Johnsen, this issue).

Since poststructuralist thought reveals its theoretical propositions through empirical cases, it makes sense to shift the discussion to an elaboration of how this school of thought has informed fisheries research in practice. In the next section, we follow J.K. Gibson-Graham's (2008) approach to poststructural thinking in economic geography by presenting three key poststructural strategies or approaches. The three strategies are deconstruction, discourse and power, and performativity. We illustrate how scholars engaged in fisheries issues have used these strategies to develop new insights into fish and marine related problems. We end this section with a discussion of the politics of poststructural thinking before introducing the papers that make up this themed issue of Maritime Studies. 


\section{Deconstruction}

The strategy of deconstruction is closely associated with the work of Jacques Derrida, a French philosopher and a key figure associated with the emergence of poststructural thinking in the late 1960s. Derrida's main concern was to challenge deeply held modernist binaries that play a key role in shaping ways of knowing. These binaries constitute the world through dual structures or systems that are permanent, enclosed and defined by their opposite or 'other'. Familiar dualities that shape modernist thinking include nature/culture, human/animal, native/alien, modern/traditional, and man/ woman. Each side of the binary depends on its opposite - neither binary can exist on its own - and they relate to each other through a 'metaphysics of value' so that one side of the binary is considered to be better than the other. This metaphysics of value is most obvious in the cases of modern vs traditional and human vs animal, where the first (modern or human) is considered to be inherently more valuable than second part of the duality (traditional or animal). The strategy of deconstruction is aimed at undermining these binaries in two ways. First, deconstruction aims to show that the binaries are not discreet or separate categories, as modernist thinking would have us believe. Second, deconstruction has provided scholars with the means to challenge the essential valuation that characterises one half of the duality as necessarily better than the other. The practice of deconstruction has been especially important in the feminist movement (Howarth 2013), in political ecology (Robbins, 2007, 2011) and in development studies (Escobar 2011).

In the field of fisheries research, Kevin St Martin's (2005) work provides an outstanding example of the strategy of deconstruction in the context of the crisis facing global fisheries. He identifies a spatial binary that shapes common-sense understandings of how First World and Third World fisheries should address the challenges of overfishing and environmental degradation. While the challenges facing these fisheries in different parts of the world are broadly similar, St Martin shows that the proposed solutions are dramatically different. In the First World, the dominant solution involves the privatization and rationalization of a fisheries sector that should embrace a corporate logic. In the Third World, in contrast, the proposed solutions involve a more diverse set of practices that includes community based and artisanal fishing practices, alongside a more modern fishery. This dual framing, St Martin $(2005,959)$ argues, creates a "dominant imaginary of economy in which the First World is inscribed as coextensive with a capitalist economy and the Third World is its frontier where economic difference may exist albeit temporarily and as a deficient relative to capitalism". Deconstructing this binary allows St Martin to reveal the diversity of fishing relations within the First World, which allows opening up the possibility of more progressive strategies to address the challenges facing the fisheries sector in the First World and the communities who depend on this industry for their livelihood (also see St Martin 2001, 2006). St Martin's work represents a vivid example of deconstruction in the fisheries sector and its significance to contemporary debates on fisheries policy.

More recent work in fisheries has added to the repertoire of deconstruction by revealing how apparently stable and essential binaries - like nature and culture - vary over time and space. In this way, this work aims "to move beyond the deconstruction of dualities and to recognize and explore the ways in which human practices constantly recreate distinctions that are fundamental to our ways of knowing" (Abram and Lien 
2011, 4). Marianne Lien and John Law's recent work on salmon in Norway provides an excellent example of work that examines the making of nature/culture dualities (Law and Lien, 2012; Lien and Law, 2011). The rapid growth of farmed salmon production in Norway has led to new categories of Atlantic salmon that have been mapped on to more familiar categories of nature and culture. Prior to the emergence of aquaculture, the term wild salmon and its domesticated 'other' did not exist. It is only since the development of farmed salmon, now linked inextricably to culture, that the binary is now identifiable and real. Fish nature/cultures are not essential categories but are instead emergent, unstable and contingent.

Through their work on salmon, Lien and Law (2011) are able to show how the binaries that shape our ways of knowing are outcomes material and social networks, or 'modes of ordering'. They are not essential or foundational. The categories of wild and farmed salmon are the result of specific orderings of fish, humans and technical objects. In other words, wild and farmed salmon are the result of heterogeneous networks that enact fish as 'natural' or 'cultured'. Swanson et al. (2017) build on these insights by comparing salmon practices in Norway and the Pacific Northwest of the United States. They propose the concept 'modes of naturing', a term that captures the spatially and temporally diverse ways in which salmon become nature or culture.

Stephanie Lavau's (2011) work on the management of fish in Australian rivers points to other ways in which 'modes of naturing' are done in practice. Healthy rivers in the Australian context are usually linked to the presence of native species of fish, which deserve protection and care. Alien species of fish, in contrast, are usually seen as a threat and out of place in natural and healthy river environments. Yet, as Lavau argues, this is only one way in which the 'naturalness' or ecological health of rivers can be secured and sustained. She identifies competing discourses in which river health may be achieved including models and approaches that stress wildness and ecological functionality. These competing visions imply different management strategies from those that would protect native species of fish while eradicating fish considered to be alien to natural river environments. Nature is not, Lavau (2011) writes, 'a fixed and discoverable category'. It is instead a relation that is brought into being through socio-material practices that enact fish as wild or farmed/native or alien. Intriguingly, Lavau (2011) connects her work on fish indigeneity to hotly contested debates in Australia on citizenship and immigration. What might we learn, she asks, about 'fish citizenship', belonging and responsibility in a context of increasing flows of humans and animals?

The idea that we take fish-human relations seriously and explore their implications for broader discussions about nationhood and citizenship is also a key theme in Zoe Todd's (2014) work on fish and political processes of reconciliation for Indigenous groups in northern Canada. Her work is based in the territory of Nunavut, and she explores fish-human relations as 'sites of engagement' that challenge existing Western modes of understanding. In these sites of engagement, fish are singular and plural, leading to a multiplicity of relationships with humans. These relationships reflect Indigenous cosmologies and, as Todd argues, must be acknowledged in contemporary processes of reconciliation for Indigenous groups in her study site and beyond in Canada.

Fisheries scholars have used the strategy of deconstruction to trouble and challenge modernist binaries that often provide the foundation for how we understand the relations between fish and humans. Challenging these binaries is not simply an intellectual 
exercise. On the contrary, as the work of St Martin and others has shown (e.g. Lien 2012; Daniels and Mather, this issue), deconstructing modernist binaries can open the way for new and progressive ways of addressing the key challenges facing contemporary fisheries.

\section{Discourse and power}

The concept of discourse and its relationship to knowledge, truth and power is attributed to the work of Michel Foucault, widely considered to be a key thinker in poststructural thought (even though he publically resisted being pigeonholed within any specific scholarly tradition, see Howarth 2013; Williams 2005). Foucault brought an important historical sensibility to existing poststructural work that challenged contemporary western and modernist ways of knowing. Drawing on historical cases and detailed archival work, he demonstrated that what is considered to be 'true' at any point in time relies on discursive formations, which are systems of meaning that judge what counts as knowledge. These systems of meaning are linked to institutions such as clinics, hospitals and schools that help support and maintain discursive formations (Dean 1999). Foucault was particularly interested in how discourses associated with concepts such as madness and delinquency changed over time, which could be traced through his method of 'genealogy'. The significance of the genealogical method is that it makes explicit the process through which discourses (and social institutions) act to both normalize knowledge and behaviour while at the same time excluding other knowledges and behaviours. Discourses, for Foucault, are power laden: they provide the means to exclude and marginalize knowledge, behaviour and groups.

While Foucault's earlier work was concerned with the operation of knowledgepower through discourses associated with madness, sexuality and delinquency, his later work developed these insights in the context of state power through what he called 'governmentality'. For Foucault, governmentality represented a new mode of governing where the aim is to guide and regulate human behaviour (or conduct) through specific rationalities, and supported by new modes of calculation and technologies (Sønvisen, this issue). The concept of governmentality provided several radical new propositions for understanding state power. First, by arguing that governmentality involves shaping and directing human conduct, Foucault drew attention to the importance of self-regulation as a mode of exercising power. The emphasis on state efforts to direct human conduct suggested a more complex and distributed understanding of power. A second and closely related point is that these attempts to regulate human conduct exist in a wide range of institutions and contexts that go far beyond formal state structures. We can see governmentality and the effort to direct human conduct in schools, the workplace and even in the home. A third proposition associated with governmentality has to do with ethics and morality. Because governmentality involves action aimed at governing ourselves, it is an intensely moral issue. It asks us to question our behaviour in the context of who and what we should be.

Fisheries researchers have been especially effective in deploying Foucault's concepts of discourse and governmentality in the context of resource privatization for fisheries in Europe, North America and Australasia (Pinkerton and Davis 2015; Johnsen 2014; Massey and Rees 2004). A key contribution of this work has been to reveal rationalities 
that support the neoliberal privatization of fisheries across many different contexts. In her work on fisheries in Alaska, Courtney Carothers and Catherine Chambers have provided convincing evidence on how discourses of neoliberal rationalization rely on the rationality of neoclassical economics. These discursive formations, they argue, "make these logics appear natural, defining features of human society" (Carothers and Chambers 2012, 41). Indeed, a key characteristic of discursive formations is that their rationalities become to appear truthlike and beyond critique, making it difficult to "imagine how things could have been ordered differently" (Carothers 2008, 59, also see Carothers 2010; McCay 2008; Langdon 2017). As we noted earlier, Foucault was able to show how discursive formations exercise power by excluding particular practices and the groups associated with these practices. Carothers and Chambers' $(2012,51)$ work in Alaska provides a stark illustration of this process: they find that neoliberal discourses marginalize individuals and groups associated with place-based and community oriented fishing practices who "become increasingly portrayed as irrational users or unproductive, redundant, expendable labour".

While Carothers and Chambers are concerned with neoliberal rationalities in wild capture fisheries, Jennifer Silver's research (2013) in British Columbia provides key insights into the operation of governmentality in the context of an emerging aquaculture sector. She argues that government policies to encourage aquaculture development are informed by neoliberal rationalities and calculative measures that attempt to discipline both space and subjectivities so that "new growing regions understood to be ecologically and socio-culturally amenable with shellfish aquaculture might emerge" (Silver 2013, 431). Governmentality in Silver's case involves the imposition of new spatial imaginaries and an attempt to reshape subjectivities and identities to make coastal regions attractive to aquaculture development. All of this work on the contemporary transformation of fisheries suggests that the imposition of new regimes in fisheries through neoliberalization may be understood in terms of what Foucault would have called a 'programme of conduct', which involves "more or less explicit, purposive attempts to organize and reorganize institutional spaces, their routines, rituals and procedures, and the conduct of actors in specific ways" (Dean, 1999, 32; also see Song, 2015; Johnsen, this issue).

\section{Performativity}

The third strategy associated with poststructural thinking is associated with the concept of performativity. The idea of performativity challenges the idea that our knowledge practices only describe the world. In structuralist thinking, our models and theories are considered to be independent from an independent reality, a separate world 'out there'. Poststructural thinking proposes a more complex and dynamic relationship between the methods and techniques that scientists, policy makers and academics use to describe the world and how the world 'is'. For poststructuralists the models, theories and frameworks that we use to understand the world can be performative. They can, in other words, play a role in shaping the world; they can be 'world making'. This shift between structural and poststructural thinking is often described as a shift from epistemology to an engagement with questions of ontology.

The key idea here is that our methods and models do not only describe the world, they also help shape it. While this may seem an extraordinary statement to make, 
fisheries scholars have used this insight in productive ways to analyse the transformation of fisheries in different contexts. Holm and Nielsen's (2007) work on changes in fisheries management in Norway during the 1980s and 1990s represents one of the earliest and perhaps best-known examples of economic performativity in fisheries research (also see Holm 1996, 2007). Their analysis focuses on the effort to introduce Individual Transferable Quotas (ITQ), a management model inspired by neo-classical economics aimed at creating perfect market conditions in the fishery. Although the model failed to transform fishing in Norway in the way neo-classical economists predicted or hoped, it nonetheless had enormous and far-reaching effects on everything associated with fish: it transformed fish into tradeable commodities even before they are landed on the boat, it changed harvesters into property owners and profit maximisers, and it dispossessed many harvesters and most crew from the benefits of this new regime.

Holm and Nielsen (2007) are careful to point out that the economic theories that exist in textbooks, and that inform ITQs, do not simply and easily transform the real economy. On the contrary, the move from economic theory to economic reality is contingent and complex, and depends on much more than a textbook theory of how the economy should operate. In the Norway case, Holm and Nielsen (2007) identify the 'TAC machine', a complex assemblage of humans, non-human animals, and tools that are combined with new methods of calculation and measurement that transform the fishery. As Holm writes, ITQs depend on.

"the construction and stabilization of a heterogeneous network, tying the fish in with fishermen, echo integrators, log books, legislation, computers, bureaucracies, mathematical formulas, and surveillance procedures" (Holm, 2007, 239).

Holm's $(2007,238)$ writing on changes in fisheries management in Norway suggests that we pay close attention to "that first precarious leap from economic textbook into practice". His use of the term 'precarious' is deliberate. It signals the challenge of turning economic theory into economic reality, and it points to the fragility of the heterogeneous networks that enact economic and social change. These networks require maintenance, they are precarious and they may break down. The word choreography is often used to describe these heterogeneous networks - or assemblages - as a way of signalling their fragility and vulnerability to disruption and dissolution.

The emphasis on the contingency of economic performativity has led fisheries scholars to examine situations where economic models have failed to remake the world as economists expect. Karen Hebert's $(2010,2014)$ work on Alaskan salmon provides an outstanding example, and her work, together with the contributions by Holm and Nielsen, has brought the case of fisheries into conversation with a broader literature on economic performativity. She asks "why certain economic models seem to smoothly reconfigure the world in their image, while others gain little traction, never moving much beyond the drawing board?" (Hebert, 2014, 21-22). Hebert's research is situated in Bristol Bay Alaska where the salmon industry has been under pressure to rationalise and to meet new and stringent quality standards associated with niche markets and in the face of competition from the farmed salmon industry. Her argument is that the market devices aimed at restructuring economic activity do not mirror economic reality, in part because they "bump up against other kinds of obdurate matter" (Hebert, 2014, 23). The 'obdurate matter' that Hebert identifies includes the historical context of 
salmon fishing in Bristol Bay, the limits to which market devices can transform fishy matter, and the resistance by salmon harvesters to new economic ways of being. If economic theory does not easily transform economic life in Bristol Bay, then what does it do? Hebert's answer is in line with Holm and Nielsen's work in Norway: although the model appears to fail, it nonetheless changes economic conditions while at the same time adding new indeterminacy to economic activity (also see Cardwell, 2015).

Research in the North Atlantic provides additional evidence of the complex relationship between economic theory and economic life. Camilla Brattland's (2014) research on indigenous Sami fishers in Norway examines the pressures facing small-scale harvesters in a context of 'cybernetic' restructuring. The term 'cybernetic' in the context of fisheries transformation refers to Johnsen et al.'s (2009) excellent comparative work on changes in Newfoundland and Norway fisheries. Through detailed analysis of these two key North Atlantic fishing sites, they identify three modes of ordering fisheries that have shaped the industry since the early 1900s: organic, mechanistic and cybernetic. Each mode or phase of fishery development is associated with a different combination (heterogeneous network) of technology, regulation and fisher identity. Drawing on detailed research in Norway's Porsanger fjord fishery, Brattland's research asks how and whether these three categories 'fit' the Sami case. Her argument is that although the cybernetic fishery has changed Sami small scale fishing, it is nonetheless important to recognise the diversity that exists within a sector that has often been treated as homogenous. Through her case on Sami fisheries, Brattland's $(2014,4)$ points to the importance of making space for "more heterogeneous networks of relations where different forms of assemblage are allowed to exist in diverse and hybrid forms". JK Gibson-Graham's (2006) work on diverse economies, which we discuss in more detail below, is an important conceptual anchor for Brattland's work as it allows her to account for the diversity of economic outcomes in real world economies.

The concept of performativity has been important for researchers examining the impact of stock assessment models. These models have become key tools for fish resource managers who use it to determine total allowable catches for specific fish species. Stock assessment models have played a particularly important role since the late 1970s when most states declared 200-mile exclusive economic zones, and they are, of course, part of the heterogeneous network that has facilitated individual property rights in some fisheries. While these models are seen as crucial to sustainable resource management, fisheries scholars working from a poststructural sensibility have explored the performative effects of stock assessment. As Sally Eden $(2012,1017)$ writes, the focus is on how these models "move fish from the water of the river to the paper of reports and policy, so that data are performative and creative of new realities".

A key focus in the research on stock assessment models is the role they play in transforming fleshy fish and complex human fishers into abstractions that behave according to universal laws. Drawing on the Canadian context of northern cod collapse, Bavington $(2009,112)$ argues that the effect of stock assessment models was to turn northern cod into "members of large swimming inventories whose current and future biomass and economic value could be assessed onshore long before any cod were killed by a fisherman or had spawned offshore". Yet as is the case with economic theory, stock assessment models are unable to reshape reality in a straightforward way. The fleshy vitality of fish and the complexity of fishers exceed the model's categories and algorithms. 
While the resource models transform fish and the people who harvest and process this resource into commodities for sale, they are not able to perfectly impose their models on what are unruly and impossible to control relationships. Indeed, in many cases their effect has been the opposite of what was intended: "management and governance systems seem to have contributed what they were ostensibly designed to prevent - stock collapses and increased harvesting capacity" (Johnsen et al., 2009, 27). Yet as is the case with economic performativity, the failure to reshape reality does not mean that these models have no effect on real world processes (Johnsen this issue; Sridhar, this issue).

The abstractions that are central to stock assessment models stand in stark contrast to a rich vein of research that has explored the complex and changing relationships between fish and humans in specific contexts. Two articles stand out, both of which coincidentally carry the title 'thinking like a fish' (Bear and Eden, 2011; Duggan et al. 2014). The cases are from very different contexts: the first is based on the experiences of small scale harvesters in Stillbaai, South Africa (Duggan et al. 2014) while the second draws on the practices of anglers on three ecologically diverse rivers in northern England (Bear and Eden 2011). Despite the different contexts, both studies stress that fish and fishers/anglers are made relationally in the entanglement that brings them together; the relationship between fishers/anglers and the fish is complex, contingent and continually on the move. There is thus no essential category of 'fish' or 'human angler/ fisher' in this work - both are the outcome of relational be-comings (Daniels and Mather, 2017). While the cases draw from different contexts, the lessons for resource management are similar. For Bear and Eden (2011), attending to anglers and their efforts to think like a fish is important for fish management practices as the anglers and the fish they encounter play a key role in the changing ecology of river systems. The research based in Stillbaai points to the limits of stock assessment models and to new ways of approaching resource management: 'thinking like a fish' holds the potential to move beyond traditional mathematical, biologically-focussed discussions in the Stilbaai fishery by allowing for a rethinking of the ways in which human-fish interactions are framed and carried out" (Duggan et al. 2014, 3).

\section{Poststructural politics}

Given these different strategies associated with poststructural thinking, it is perhaps not surprising that it is difficult to identify within this tradition a single 'theory of politics'. This is not to say, as some have argued, that postructuralism lacks a strong commitment to political change (see Howarth 2013, 70-75). On the contrary, the politics of poststructural scholarship, as we argue below, is implicit in these strategies and the worlds that they perform.

JK Gibson-Graham's work on diverse economies provides a clear illustration of the politics implicit in the strategies of deconstruction and performativity. Her work has focused on deconstructing the capitalist/non-capitalist binary that is so central to modern Western thinking. This deconstructive move asks us to 'read for difference' in the real economy, which reveals an economic landscape that is characterised by "a myriad of contingent forms and interactions" (Gibson-Graham 2006, 54; St Martin et al. 2015). Revealing the economy as diverse and contingent is key to remapping and re-imagining the economy as something that is not given and transcendental, but an economy that is framed as a political and ethical space of decision. Deconstructing binaries and reading 
for difference is a political intervention that disrupts existing ways of thinking and provides the space to think and practice progressive alternatives. We discussed St Martin's earlier work on New England fisheries, which deconstructs global dualities and allows for new ways of thinking about fishing communities in this region and beyond. His more recent work provides further insights into the politics of poststructural scholarship through a Community Supported Fisheries (CSF), the marine equivalent of the more established practice of community supported agriculture (Synder and St Martin 2015). The Port Clyde CSF has become the basis and the inspiration for new and progressive economic relations that are embedded in this organisational form. As Snyder and St Martin $(2015,27)$ argue, the CSF performed the local community, and their relationship to the marine environment, in a new and hopeful way: 'Rather than the individual and self-interested 'fishermen' (and consumer) presumed by fisheries science and management, CSFs call us to be stewards of the environment, to be committed to one another's well-being, and to reimagine the direction of our local economies and environments". The significance of their work is that deconstruction and reading for difference provides the space to rethink dominant approaches to fisheries management.

The concept and practice of ontological politics is another way of thinking about politics in poststructural scholarship and thought (Mol 2002; Probyn 2016). The idea of ontological politics builds on the poststructural sensibility that our worlds are the result of situated and precarious assemblages of humans, animals and things. Significantly, it tells us that 'things could be otherwise', and that what exists now is not the only way of assembling social reality. Boucquey (2015) et al. have used these insights to explore the ontological politics of Marine Spatial Planning (MSP), which is widely seen as a rational approach to managing complex and contested oceans spaces. Although MSP can frame and enact spaces and communities in ways that are far removed from the lived experience of people living on the coast, this is not an inevitable outcome of MSP. Planning tools like MSP, Boucquey et al... argue, can be 'assembled' differently in ways that destabilize the relationship between planners and coastal communities, while at the same time providing the foundation for a more progressive and hopeful way of living in ocean spaces (also see Fairbanks et al. 2017). Bouquey et al's (2015) research is an excellent example of ontological politics and it confirms a point that John Law $(2009,155)$ has long stressed: he has argued that "reality is not destiny" and that with "great difficulty and effort, what is real can be remade". If there is a core to poststructural politics, it is this: the potential and the possibility of being able to remake the real.

We have argued in this introductory paper that there is a strong tradition of poststructural inspired research that has informed how we understand and respond to the economic and social transformation of fisheries in different maritime contexts. This work has provided key insights into some of most significant socio-environmental changes that have affected harvesters, fishing communities, and, of course, the fish themselves. Yet the intellectual traffic has not only been one way. Research by fisheries scholars on ITQs, market devices, community economies associated with fish and humans, and the problems with nature/culture binaries has added to the broader repertoire of poststructural thought. Having laid the conceptual groundwork, we now turn to introduce the papers that follow in this special issue of Maritime Studies. 


\section{The collection of papers}

The special issue consists of five papers that represent original studies and draw from research conducted in Norway, Canada, and India and Sri Lanka. All of the papers draw on traditions of poststructural thought to consider change and transformation in the marine environment. Individually and collectively the papers aim to address the question of how poststructural thinking helps us to see the world differently, and to what effect.

The first paper in the collection is by Johny Stephen who focuses on the relative power of the Trawl fishers of India and the small scale fishers of Sri Lanka who 'share' the Palk Bay fishing grounds. The paper represents a revision of earlier work that sought to understand the source of Indian fishers power over their Sri Lankan counterparts in the context of resource conflicts and geopolitics in Palk Bay. While the earlier collaborative papers have argued that Indian fishers had greater agency, in this paper Stephen revisits the argument by drawing on poststructural sensibilities to develop an alternative understanding of power among the Indian trawlers using Actor Network Theory. In Actor Network Theory, power is not a sovereign property of an individual or an organisation. Instead, it is the outcome of heterogeneous networks. As Barnes $(2002,508)$ writes in a different context, networks "are sodden by power". Stephen uses this sensibility to show that Indian fishers are more powerful because they are part of an extended network that includes field correspondents, mobile phones, television sets, and good road and rail links. These are the heterogeneous networks that allow Indian fishers privileged access to the valuable fish resource in Palk Bay. The lesson of his analysis for fisheries scholars that exploring agency/power in the context of fisheries conflict can lead to a set of heterogeneous networks that lie well beyond what is understood in traditional fishery systems.

Aarthi Sridhar's contribution to this themed issue brings into play the 'disciplines' of history of science and science studies. She examines fisheries science practices in colonial India, focusing on early efforts for the preservation and enhancement of pearl oyster beds in the Gulf of Mannar, India. She does this by following Michel Callon's sociology of translation to examine historical texts. There are two key moves in her work: first, she examines an historical set of actions - what we would now call the 'resource management' of pearl oyster beds. In a move that is consistent with poststructural thought, the productivity of these oyster beds, and the pearls they hold, depend on a wide range of human and non-human actants; how one reads into (performs) this network is equally important in determining its eventual effects. Her archival work traces the work involved in colonial world-making, particularly those related to inscription and erudition. A second move in Sridhar's contribution addresses the value of transgressing disciplinary boundaries by examining what history and actor-network theory do to and for each other. Here she draws attention to the idea of texts being actors in their own right, but also "simultaneously networks associated with other texts", rather than archives of actor-networks. The strength and innovation of her work is to bring poststructural sensibilities to the performance of historical research on scientific practices in fisheries.

Within poststructural thought there is considerable diversity in how performativity is conceptualised (Mackenzie et al., 2007). Two papers in this special issue that engage with performativity reflect this diversity. Signe Sønvisen and her colleagues' contribution on the Body Mass Index (BMI) for fishers in Norway provides a unique insight 
into how new regulations are attempting to reshape bodies to produce a healthy and safe fisher. But there is more to the new rules around body mass: they intersect with a range of other matters of concern around fishing in Norway including absenteeism, fleet structure and the rationality and productivity of individual fishers and Norway's fishing industry. The rules enact an obese fisher who is considered to be "an irrational actor who does not take care of himself, his own safety or welfare through engaging in risk reduction strategies”. Drawing on personal testimonies and interviews, Sønvisen and her co-authors interfere with this narrative by examining the contradictions and inconsistencies of this new discourse on BMI and fishers in Norway. This is an important contribution to a literature on fisheries governance that has examined how policies have attempted to regulate fish, boats and gear, but rarely fisher bodies (also see Sønvisen 2013).

Jahn Petter Johnsen's contribution is also concerned with new state regulation, but his focus is on the long history of spatial regulation in Norway's fishing industry. Area regulation, he argues, has mainly been seen as an instrument for creating order at sea. He shows that area regulation has been used to secure space for fishers, to promote change and equity, protect habitats and to solve conflicts over resource use. He is concerned with how state policy, and knowledge practices, reduces the complexity of the 'things' it attempts to manage to facilitate intervention: "the instruments that are used reduce the system's complexity into governable objects and governance actions". In this way, Johnsen's work contributes a fisheries case to what is a much larger body of critical work on state policy on natural resources (cf. Robbins, 2007; Davis, 2014; Davis and Zanotti, 2014; Song 2015).

In the final contribution to the special issue, Jennifer Daniels and Charles Mather explore the material politics of Atlantic salmon conservation on the island of Newfoundland. Drawing on new materialist approaches to 'nature' and recent poststructural scholarship on the significance of socio-material practices, their work examines the heterogeneous networks that have over time connected humans and salmon bodies. Daniels and Mather argue that these practices enact different social orders, and different salmon 'reals', and imply different commitments to conservation and care. Attending to different salmon-human entanglements, they argue, interferes with the dominant narrative of Atlantic salmon conservation and opens up space for a 'companion species worldliness' that is central to Donna Haraway's project of multi-species responsibility.

\section{Openings...}

As we noted earlier, our contribution to fisheries research through this special issue of Maritime Studies is an exercise in framing. By drawing together previously published work on fisheries in the Introduction, and by presenting a set of original papers that draw on poststructural thinking, we are hoping to both name and elevate a tradition of scholarship on fisheries. Poststructural thinking tells us that our success in framing will depend on fisheries scholars continuing to explore the use of poststructural thinking in a marine context. So rather than 'concluding' this introduction we hope that the special issue provides an 'opening' for future scholarship that is inspired by poststructural thought. 
Authors' contributions

Charles Mather is responsible for writing an initial draft of this Introduction and the rest of the authors contributed equally to the final paper. All authors read and approved the final manuscript.

\section{Funding}

This research received no funding.

\section{Authors' information}

Charles Mather is a professor in Geography at Memorial University. Jahn Petter Johnsen is a professor in the Norwegian College of Fisheries Science, University of Tromso. Signe Sonvisen is Research Director at SINTEF Ocean Norway. Aarthi Sridhar is a PhD candidate at the University of Amsterdam. Johny Stephen is Assistant Professor at the Tata Institute of Social Sciences (TISS), Hyderabad.

\section{Competing interests}

The authors declare that they have no competing interests.

\section{Publisher's Note}

Springer Nature remains neutral with regard to jurisdictional claims in published maps and institutional affiliations.

\section{Author details}

${ }^{1}$ Memorial University of Newfoundland, St. John's, Canada. ${ }^{2}$ Norweigian College of Fisheries Science, The Arctic University of Tromso, Tromso, Norway. ${ }^{3}$ SINTEF Ocean, Trondheim, Norway. ${ }^{4}$ Amsterdam Institute of Social Science Research, University of Amsterdam, Amsterdam, The Netherlands. ${ }^{5}$ Tata Institute of Social Sciences (TISS), Hyderabad, India.

Received: 3 November 2016 Accepted: 9 October 2017

Published online: 15 November 2017

\section{References}

Abram, S., and M.E. Lien. 2011. Performing nature at World's ends. Ethnos 76 (1): 3-18.

Amariglio, J. 1998. Poststructuralism. The Handbook of Economic Methodology, eds. John B. Davis, D. Wade Hands, and Uskali Maki, Edward Elgar, London. 382-388.

Barnes, T.J. 2002. Performing economic geography: Two men, two books, and a cast of thousands. Environment and Planning A 34 (3): 487-512

Bavington, D. 2009. Managing to endanger: Creating manageable cod fisheries in Newfoundland and Labrador, Canada. Maritme Studies 7 (2): 99-121.

Bear, C., and S. Eden. 2011. Thinking like a fish? Engaging with nonhuman difference through recreational angling. Environment and Planning D: Society and Space 29 (2): 336-352.

Boucquey, N., L. Fairbanks, K.S. Martin, L.M. Campbell, and B. McCay. 2016. The ontological politics of marine spatial planning: Assembling the ocean and shaping the capacities of 'community' and 'environment'. Geoforum 75: 1-11.

Brattland, C. 2014. A cybernetic future for small-scale fisheries. Maritime Studies 13 (1): 1-21.

Cardwell, E. 2015. Power and performativity in the creation of the UK fishing-rights market. Journal of Cultural Economy 8 (6): 705-720.

Carothers, C. 2008. 'Rationalized out': Discourses and realities of fisheries privatization in Kodiak, Alaska. American Fisheries Society Symposium 68: 55-74.

Carothers, C. 2010. Tragedy of commodification: Displacements in Alutiiq fishing communities in the Gulf of Alaska. Maritime Studies 9 (2): 95-120.

Carothers, C., and C. Chambers. 2012. Fisheries privatization and the remaking of fisheries systems, Environment and Society. Advances in Research 3: 39-59.

Chaffee, D., and C. Lemert. 2009. Structuralism and poststructuralism. In The Blackwell companion to social theory, ed. B. S. Turner, 124-140. London: Blackwell.

Daniels, J., and C. Mather. 2017. Conserving Atlantic salmon 'after nature' on Newfoundland's gander river. British Journal for the History of Science Themes: 1-23. https://doi.org/10.1017/bjt.2016.15.

Davis, R. 2014. A cod forsaken place?: Fishing in an altered state in Newfoundland. Anthropological Quarterly 87 (3): $695-726$

Davis, R. and L. Zanotti. 2014. Introduction: Hybrid landscapes: Science, conservation, and the production of nature. Anthropological Quarterly 87 (3): 601-611.

Dean, M. 1999. Governmentality: Power and rule in modern society. London: Sage.

Duggan, G.L., L.J. Green, and A. Jarre. 2014. 'Thinking like a fish': Adaptive strategies for coping with vulnerability and variability emerging from a relational engagement with kob. Maritime Studies 13 (1): 1-21.

Eden, S. 2012. Counting fish: Performative data, anglers' knowledge-practices and environmental measurement. Geoforum 43 (5): 1014-1023.

Escobar, A. 2011. Encountering development: The making and unmaking of the third world. Princeton University Press.

Fairbanks, L., L.M. Campbell, N. Boucquey, and K. St. Martin. 2017. Assembling enclosure: Reading marine spatial planning for alternatives. Annals of the American Association of Geographers: 1-18.

Gibson-Graham, J.K. 2006. A Postcapitalist politics. Minneapolis: University of Minnesota Press.

Gibson-Graham, J.K. 2008. Poststructuralist interventions. In A companion to economic geography, ed. E. Sheppard and T. Barnes, 95-110. London: Wiley.

Hébert, K. 2010. In Pursuit of singular salmon: Paradoxes of sustainability and the quality commodity. Science as Culture 19 (4): 553-581. 
Hébert, K. 2014. The matter of market devices: Economic transformation in a southwest Alaskan salmon fishery. Geoforum 53: 21-30.

Holm, P. 1996. Fisheries management and the domestication of nature. Sociologia Ruralis 36 (2): 177-188.

Holm, P. 2007. Which way is up on Callon? In Donald MacKenzie, Fabian Muniesa and Lucia Siu (eds) Do Economists Make Markets? On the performativity of economics, 225-243. Princeton: Princeton University Press.

Holm, P., and K.N. Nielsen. 2007. Framing fish, making markets: The construction of individual transferable quotas (ITQs). The Sociological Review 55 (s2): 173-195.

Howarth, D. 2013. Poststructuralism and after: Structure. Palgrave, London: Subjectivity and Power.

Johnsen, J.P. 2014. Is fisheries governance possible? Fish and Fisheries 15: 428-444.

Johnsen, J.P., P. Holm, P. Sinclair, and D. Bavington. 2009. The cyborgization of the fisheries. On attempts to make fisheries management possible. Maritime Studies 7 (2): 9-34.

Johnsen, J.P., G. Murray, and B. Neis. 2009. North Atlantic fisheries in change - From organic associations to cybernetic organizations. Maritime Studies 9 (2): 55-82

Langdon, S.J. 2017. Approaching leviathan: Efforts to establish small-scale, community based commercial salmon fisheries in southeast Alaskan indigenous communities. In Fisheries, Quota Management and Quota Transfer, MARE publication series, 15, ed. G.M. Winder, 197-215. New York: Springer.

Latour, B. 2005. Reassembling the social: An introduction to actor-network-theory. Oxford: Oxford University Press.

Lavau, S. 2011. The nature/s of belonging: Performing an authentic Australian River. Ethnos 76 (1): $41-64$

Law, J. 2008. On sociology and STS. The Sociological Review 56 (4): 623-649.

Law, J. 2009. Actor network theory and material semiotics. In The Blackwell companion to social theory, ed. B.S. Turner, 141-158. London: Blackwell.

Law, J., and M. Lien. 2012. Slippery: Field notes on empirical ontology. Social Studies of Science 43 (3): 363-378.

Law, J., and V. Singleton. 2014. ANT, multiplicity and policy. Critical policy studies 8 (4): 379-396.

Lien, M.E. 2012. Salmon trajectories along the North Pacific rim. In B.J. Colombi and J.F brooks, keystone nations: Indigenous peoples and salmon across the North Pacific, School for Advanced Research, Santa Fe, NM, 237-255.

Lien, M.E., and J. Law. 2011. 'Emergent aliens': On Salmon, nature, and their enactment. Ethnos 76 (1): 65-87.

MacKenzie, D.A., F. Muniesa, and L. Siu. 2007. Do economists make markets? On the performativity of economics. Princeton: Princeton University Press.

McCay, B. 2008. Introduction: Ethnography and enclosure of the marine commons. American Fisheries Society Symposium 68: 1-11.

Mol, A. 2010. Actor-network theory: Sensitive terms and enduring tensions. Kö/ner Zeitschrift für Soziologie und Sozialpsychologie. Sonderheft 50: 253-269.

Murdoch, J. 2006. Poststructuralist geography: A guide to relational space. London: Sage.

Pinkerton, E., and R. Davis. 2015. Neoliberalism and the politics of enclosure in north American small-scale fisheries. Marine Policy 61: 303-312

Probyn, E. 2016. Eating the ocean. Duke University Press.

Robbins, P. 2007. Nature talks back: Studying the economic life of things. In (2007). Politics and practice in economic geography, ed. A. Tickell, E. Sheppard, J. Peck, and T.J. Barnes, 49-59. Sage.

Robbins, P. 2011. Political ecology: A critical introduction. London: Wiley.

Silver, J.J. 2013. Neoliberalizing coastal space and subjects: On shellfish aquaculture projections, interventions and outcomes in British Columbia, Canada. Journal of Rural Studies 32: 430-438.

Snyder, R., and K. St Martin. 2015. A fishery for the future. The Midcoast Fishermen's association and the work of economic being-in-common. In Making other worlds possible: Performing diverse economies, ed. G. Roelvink, K. St Martin, and J.K. Gibson-Graham. Minneapolis: University of Minnesota.

Song, A.M. 2015. Pawns, pirates or peacemakers: Fishing boats in the inter-Korean maritime boundary dispute and ambivalent governmentality. Political Geography 48: 60-71.

Sønvisen, S.A. 2013. Recruitment to the Norwegian fishing fleet: Storylines, paradoxes, and pragmatism in Norwegian fisheries and recruitment policy. Maritime Studies 12 (8): 1-26.

St Martin, K. 2001. Making space for community resource management in fisheries. Annals of the Association of American Geographers 91 (1).

St Martin, K. 2005. Mapping economic diversity in the first world: The case of fisheries. Environment and Planning A 37: 959-979.

St Martin, K. 2006. The impact of 'community' on fisheries management in the US northeast. Geoforum 37: 169-184.

St Martin, K., G. Roelvink, and J.K. Gibson-Graham. 2015. An economic politics for our time. In Making other worlds possible: Performing diverse economies, ed. G. Roelvink, K. St Martin, and J.K. Gibson-Graham. Minneapolis: University of Minnesota.

Steinberg, P.E. 2011. The Deepwater horizon, the Mavi Marmara, and the dynamic zonation of ocean space. The Geographical Journal 177: 12-16.

Swanson, H., Law, J., and Lien, M. (forthcoming). Modes of Naturing: Or stories of salmon, in T. Marsen, The Sage Handbook of Nature, sage, London.

Todd, Z., 2014. Fish pluralities: human-animal relations and sites of engagement in Paulatuuq, Arctic Canada, Inuit Studies, 38(1-2), 217-238.

Williams, J. 2005. Understanding Poststructuralism. Chesham, UK: Acumen. 